\title{
TIME SERIES OF SALT CRUSTS IMAGED BY A DUAL POLARIZATION SPACEBORNE SYNTHETIC APERTURE RADAR (SAR) AT C-BAND OVER AN ANDEAN ALTIPLANO SALAR OF NORTHERN CHILE
}

\author{
M. Barber ${ }^{1,2 *}$ A. Delsouc ${ }^{1}$, W. Perez ${ }^{3}$, I. Briceño ${ }^{3}$ \\ ${ }^{1}$ Magíster en Teledetección, Escuela de Ingeniería Forestal, \\ Facultad de Ciencias, Universidad Mayor, Santiago, Chile - analia.delsouc@ mayor.cl \\ ${ }^{2}$ Grupo de Teledetección Cuantitativa, \\ Instituto de Astronomía y Física del Espacio (IAFE, CONICET-UBA), Buenos Aires, Argentina - mbarber@iafe.uba.ar \\ ${ }^{3}$ Hémera Centro de Observación de la Tierra, Escuela de Ingeniería Forestal, \\ Facultad de Ciencias, Universidad Mayor, Santiago, Chile - (waldo.perez,idania.briceno)@ mayor.cl
}

KEY WORDS: Salar, halite growth, salt crust, rough surface, synthetic aperture radar (SAR), radar remote sensing, Sentinel 1

\begin{abstract}
:
A dense time series of Synthetic Aperture Radar acquisitions at 6-day intervals between July 2017 to January 2019 collected with the C-band constellation Sentinel 1A and 1B is used to study salt crust evolution in an highland salar. Microwave response of halite crystal aggregates is linked to surface roughness of the salt crusts by means of a surface scattering model which includes multiple scattering at second order in media with complex permittivity such as brine-soil mixtures. The time series enabled to estimate co-polarised vertical-vertical backscattering coefficient variations as large as $8.8 \mathrm{~dB}$ on a 4 -month period which implied a height standard deviation increase from 0.5 to $4.5 \mathrm{~mm}$ as modeled by the surface scattering model. Backscattering coefficient variations between 0.8 to $2 \mathrm{~dB}$ per month are found for three different crusts, which demonstrated different growth rates of the crystals. Crystal growth rate might be driven by the kind of water input (rainfall or snow in Andean salars), probably due to the negative effect of water droplets on impinging halite crystal surface in comparison to snow. Results showed that cross-polarised backscattering coefficient is sensitive to snow accumulation and appeared to be sensitive to subsurface conditions.
\end{abstract}

\section{INTRODUCTION}

Salars are natural detritical and evaporitic sedimentary environments where microwave responses are subjected to large variations over a time span of few months due to the development of halite crusts. Halite growth implied crystal aggregates of sizes ranging from millimeter to few centimeters. Thus, Synthetic Aperture Radar (SAR) sensors operating at C-band $(5.55 \mathrm{~cm})$ are useful to monitor surface changes over salars. Moreover, since power losses at $\mathrm{C}$-band result in a penetration depth lesser than $10 \mathrm{~mm}$ over the salar surface, microwave backscatter accounted for surface roughness changes with surface scattering as the dominant backscattering mechanism. Therefore, temporal changes in the time series were the result of salt crust development and their time evolution. Humidity and water availability are the main drivers for halite growth. Growth of halite through evaporation of standing water or rise of brines by capillarity leads to a high increase of the radar power backscattered (Wadge, Archer, 2003) since its surface becomes rougher to microwaves at C-band.

The chosen salar is the Salar de Aguas Calientes Sur, which has a special climatic and geographical feature. Located at 4,000 m.a.s.l. in the Andes Highlands, it has an extreme weather conditions given by high annual evaporations rates, snowfalls and rainfalls during austral winter (June to September) and Altiplanic winter in summer (December to March). Also, strong solar radiation and high-speed winds (up to $70 \mathrm{~km} / \mathrm{h}$ ) control the evaporites minerals formation. Unlike rocks, evaporitic minerals in the salar are sensitive to changes by wind, ponded water

${ }^{*}$ Corresponding author sedimentation and evaporation followed by chemical precipitation. Moreover, evaporites are also sensitive to climatic changes because the salts are dissolved either by the effect of precipitation or rise of groundwater. In the absence of these water inputs, the evaporation processes trigger changes in the salar surface, roughness and dielectric properties, due to crystallization of evaporite minerals (Frison et al., 2013). The overall information points out an evident dynamic within this detritical and evaporitic sedimentary environment, where the salt crusts have a seasonal component not yet fully undestand.

Scattering models are an useful tool to interpret the power returned by a distributed surface scatter with prescribed roughness parameters and complex permittivity, for any observation configuration. In this paper the Integral Equation Model which included multiple scattering at second order in lossy media (referred to as IEM2Mc, (Álvarez-Pérez, 2012)) is used to monitor roughness variations given the backscattered power returned to the sensor. From model simulations over bare saline soils, large backscattering coefficient variations are constrained to large increases in surface roughness. Thus, salt crust changes are inferred over the salar extent.

Dual polarization acquisition implies a two-fold transmit and receive combination which for Sentinel-1A/B derives in both co-polarized vertical-vertical (VV) and cross-polarized verticalhorizontal $(\mathrm{VH})$ backscattering coefficients. Overall, surface scattering at rough air-surface interface is the major contribution to the co-polarized scattering. For lossy media, multiple (volume) scattering at subsurface layer is the only contribution to the cross-polarized scattering (Ulaby et al., 2014, Liu et al., 2016). With halite growth, rougher surfaces coated with films 
of brine will increase volume scattering and therefore crosspolarized backscattered power (Archer, Wadge, 2001).

Research over evaporitic environments has been done (Ulaby et al., 1975, Wadge et al., 1994, Wadge, Archer, 2003, Lasne et al., 2008, Frison et al., 2013) in continental arid regions where water supply comes mostly from rainfalls, besides groundwater contributions. In highland salars, such those founded in the Andean Altiplano, snowfalls and their subsequent melting are extra water inputs. Nowadays, satellite acquisitions with high spatial (few meters) and temporal resolution (few revisit time) are available through constellations such as Sentinel 1 which enabled to monitor surface changes within a few days.

This paper is aiming at assessing the high temporal dynamics of the salar of Aguas Calientes Sur in Northern Chile by analyzing its SAR backscatter response through a multi-temporal study with a dense collection of C-band Sentinel 1A and 1B acquisitions. This Andean salar was selected because a number of optical and field data collections were carried out there. However, this salar lacks of studies in the microwave region. Salars are of great interest as for their natural resources since their subsurface brines contain valuable dissolved minerals that are often commercially exploited. Two distinctive aspects of this study in relation to previous research is that the high temporal and spatial resolutions of the time series enabled accurate linking of dry periods to crust development for three different salt crusts and that the cross-polarization backscattered power is analyzed for subsurface volume scattering contribution.

\section{MATERIAL AND METHODS}

\subsection{Study Area}

The Salar de Aguas Calientes Sur is a $476 \mathrm{~km}^{2}$ salt flat located in the high puna of northern Chilean Andes $\left(67^{\circ} 41^{\prime} 16^{\prime \prime} \mathrm{W} / 23^{\circ} 58^{\prime} 27^{\prime} \mathrm{S}\right)$, at an altitude of approximately 4,000 m.a.s.l. (Figure 1). The containing basin is endorheic and intra-volcanic. Overall, the northern, southern and margins have shallow lakes. The most abundant evaporitic minerals found in the salar are gypsum and halite.

Field observations and morphological analysis over the Salar de Aguas Calientes Sur were conducted on April 3, 2018 (Figure 2 ). Field observations showed highly heterogeneous pan crust environments that could be grouped into three different crust types. The first is a hard crust (referred to as hard pan crust 1 , Figure 2 (a)) formed primarily by gypsum, halite and detrital particles. It is characterized by an irregular concave shape, uplifted rims, and salt enrichments crystallized as granular forms and thin sheets covering the gypsum pan over the borders indicating that most of the time remains not flooded (Ruch et al., 2012). These salts with granular form, indicate that they were formed from evaporation and rise of brines by capillarity (Wadge, Archer, 2003). This crust surface is rough over microwave scales from millimeter to centimeter such that of the sensor Sentinel 1 (Barber et al., 2016). The second crust type is referred to hard pan crust 2 (Figure 2 (b)), and it is distributed along the east edge of the salar, formed by gypsum and halite containing cavities that indicate dissolution of salts due to infiltration and percolation of water causing loss of stiffness. The surface is somewhat soft, as can be noted from the footprint tracks left over as seen on the right in Figure 2 (b). A third salt crust with soft consistency is distributed over the northwest and southwest (Figure 2 (c)). Almost flat with mud-crack polygons that contains a mixture of moistened salts, mainly halite, and some gypsum. The polygons indicate water loss after flooding events (Warren, 2016). This crust is over a lower part of the pan so that it is easily flooded. Its surface appeared smooth to microwave frequencies.

Towards the north and south of the salar, a few perennial ponds are observed. The permanent inflow prevents them to drying out entirely by evaporation. In the rest of the salar, the deposition of halite and gypsum crystals through evaporation and the following halite growth by the upward movement of capillary water plays an essential role in the temporal variability of the backscattered signal on the surface of the salar.

\subsection{Multitemporal SAR data}

Sentinel $1 \mathrm{~A}$ and B constellation (C-band, $5.55 \mathrm{~cm}$ ) provided the SAR imagery for this study. Images were acquired in Interferometric Wide Swath (IW) mode, level 1 processing, and Ground Range Detected (GRD) with a spatial resolution of 20 $\mathrm{m} \times 22 \mathrm{~m}$ (range by azimuth) and a swath width of $250 \mathrm{~km}$. The Sentinel 1 dataset encompasses five acquisitions per month from July 1, 2017 to December 29, 2018, in dual polarization (VV and $\mathrm{VH}$ ) and ascending passes.

Image processing started with usual preprocessing steps such as orbit correction and thermal noise removal. Then, Sentinel 1 images are radiometrically calibrated. Subsequently, a Refined Lee filter with a $7 \times 7$ pixel window was used to improve radiometric quality. Finally, the geometric terrain correction was applied by assigning the digital elevation model SRTM 1Sec HTG and bilinear interpolation, resulting in an image with a nominal pixel size of $10 \mathrm{~m} \times 10 \mathrm{~m}$. As a final product, output bands of backscattering coefficients $\left(\sigma^{0}\right)$ for $\mathrm{VV}$ and $\mathrm{VH}$ along with their corresponding local incidence angle were generated.

\subsection{Meteorological data}

The Salar de Aguas Calientes Sur has an arid climate with a mean annual rainfall varying between $150 \mathrm{~mm}$ and $200 \mathrm{~mm}$ (Herrera et al., 2016) with $10 \%$ to $20 \%$ occurring as snowfall. The annual temperatures are between $-30{ }^{\circ} \mathrm{C}$ to $10{ }^{\circ} \mathrm{C}$, that combined with strong winds leads to high evaporation rates with an average of 1,500 mm per year (Risacher, Fritz, 2009). Daily precipitation for the study period was compiled from one ground station located in Socaire village, $49.8 \mathrm{~km}$ away to the northwest of the Salar de Aguas Calientes Sur (Agromet Home Page, 2019). Snow cover information over the salar was retrieved from a visual analysis of MODIS Terra Corrected Reflectance, true colour product from (NASA Worldview Home Page, 2019). Precipitation events from Socaire ground station and snow cover from MODIS will aid to identify the general trend of water supply to the salar area. This information will be used to determine periods where water input to the salar are available and lead to the onset of hallite growth, thus increasing the surface roughness at scales of about $1 \mathrm{~cm}$ largely influencing scatter response at $\mathrm{C}$ and $\mathrm{L}$ bands.

\subsection{Microwave rough-surface scattering of salars}

The Integral Equation Model with multiple scattering at second order for complex-permittivity media, referred to as IEM2Mc, (Álvarez-Pérez, 2012) is the name given to an improved, enhanced version of the Integral Equation Model originally developed by Fung (Fung, 1994) to describe rough-surface scattering in the field of radar remote sensing for Earth observation. 

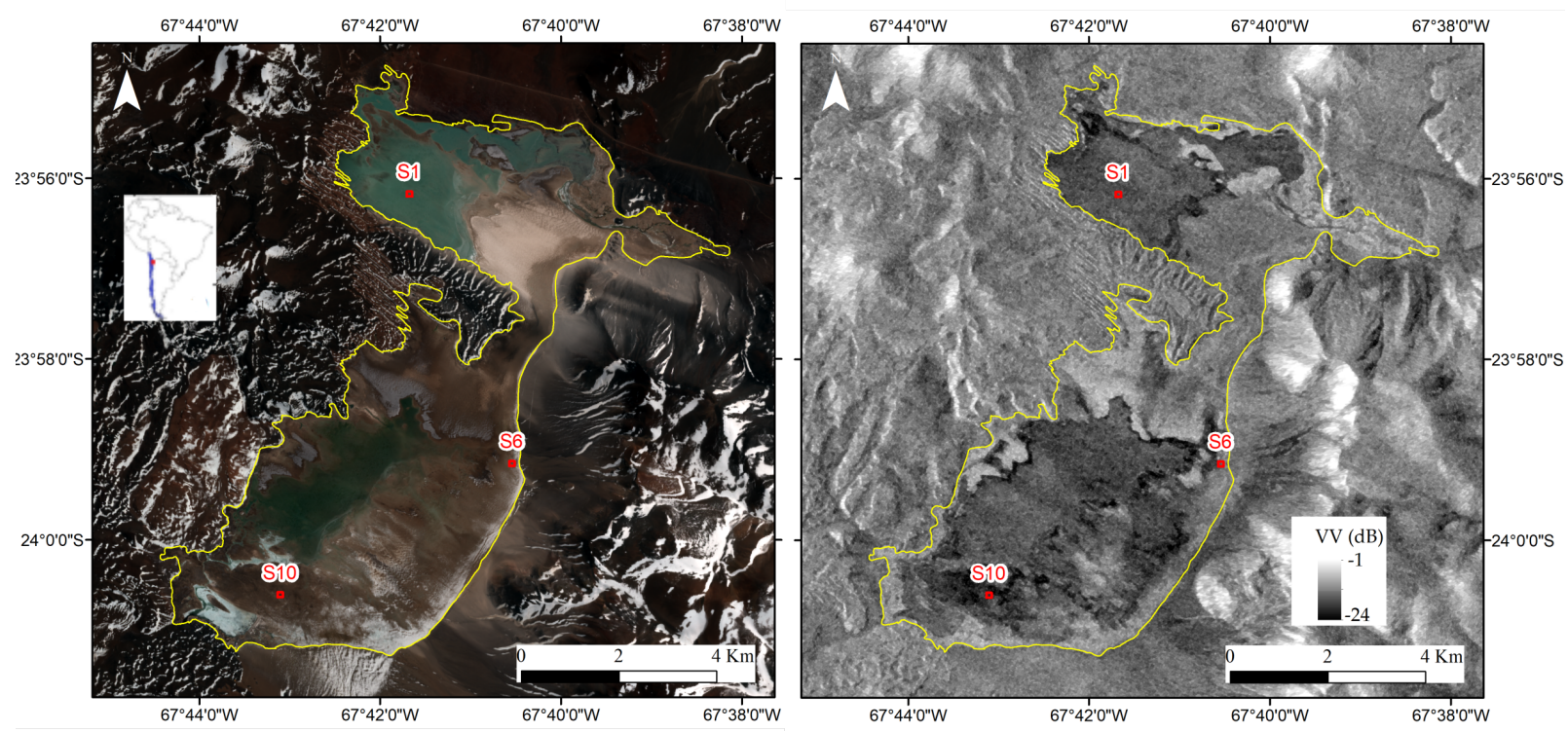

Figure 1. Study area on September 11, 2017. Left: True color (Sentinel 2). Right: C-band SAR (Sentinel 1). Center coordinates are $67^{\circ} 41^{\prime} 16^{\prime \prime} \mathrm{W}$ and $23^{\circ} 58^{\prime} 27^{\prime \prime} \mathrm{S}$.

Surface parameters for IEM2Mc are complex dielectric constant, surface standard deviation $s$, power spectrum and correlation length $l$. Research on evaporitic soils suggested $s / l \sim 0.10$ (Aly et al., 2007, Lasne et al., 2008, Liu et al., 2016), with $s$ on the millimeter scale. An exponential power spectrum is known to better fit natural surfaces (Barber et al., 2016).

Relative dielectric constant of primary constituents of dry lake saline soils are silicates $(\varepsilon=5.90)$, halite $(\varepsilon=4.48)$, and gypsum $(\varepsilon=6.88)$ (Wadge, Archer, 2003), all exhibiting a negligible imaginary part and a frequency-independent behavior in the microwave band (Ulaby et al., 2014, §4-8.1). The dielectric loss in the media is entirely given by the salts dissolved in the brine under the salt crust surface. Salinity of the water is expressed in psu which is approximately equal to parts per thousand of solid salt in grams dissolved in $1 \mathrm{~kg}$ of solution. Over the study area, subsurface brine salinity ranges between 2 and 45 psu as reported in 2013 by (Troncoso et al., 2013). A salinity of 66 psu was measured recently in the northern lake near the site S2. The brine layer within soil is a mixture consisting of solid particles and saline water allocated within soil's pores. A simple mixing model is used for modeling complex dielectric constant of saline soils. The dielectric constant of saline soil $\left(\varepsilon_{s s}\right)$ was calculated using the dielectric values calculated for dry soil $\left(\varepsilon_{d s}\right)$ and saline water $\left(\varepsilon_{s w}\right)$ following (Ulaby et al., 2014), each weighted by its respective proportion of the combined mixture,

$$
\varepsilon_{s s}=(1-\phi) \varepsilon_{d s}+\phi \varepsilon_{s w}
$$

where $\phi$ is the medium's average porosity. Typical average porosity ranges $0.34-0.45$ (Ulaby et al., 1975, Lasne et al., 2008). In Equation (1), $\varepsilon_{s w}$ is a function of frequency, salinity and, to a lesser extent, soil temperature.

\subsection{Roughness estimation from modeled $\sigma^{0}$}

Level curves of the IEM2Mc as a function of both roughness parameter $s$ and salinity of brine solution is shown in Figure 3 . It is clearly shown that surface roughness dominates the $\sigma^{0}$ response, with an almost flat response to brine salinity. As a ref- erence, other roughness parameters such as correlation length or the spectrum power account for variations of few $\mathrm{dB}$ in $\sigma^{0}$ at VV polarization. Therefore, large $\sigma^{0}$ variations are expected primarily from surface roughness variations.

\section{RESULTS}

The time series of Sentinel $1 \mathrm{VV}$-polarized $\sigma^{0}$ for each of the three crust types mentioned in Section 2.1 is shown in Figure 4. Precipitation information is also shown as a bar plot for rainfall and as occurrence instances for snowfall. In this respect, Salar de Aguas Calientes Sur underwent an increase in the available water due to persistent snowfall events and some rainfalls from July to late September 2017. The availability of water and the evaporation that followed has driven the formation of crusts and henceforth changes in surface roughness detected at C-band. The rainfalls during February 2018 prevented $\sigma^{0}$ from further increasing. Over the dry period that follows, crust development resumed until late June 2018. A third wet-and-dry cycle occurred on the dry period after October 2018.

Changes in the backscattered power showed different patterns depending on the salar spatial distribution and composition. For type 2 (S6) and type 1 (S10) hard crusts, Figure 4 (b) and (c), respectively, $\sigma^{0}$ increase-and-decrease pattern accounted for inter-annual wet and dry periods. This is more evident on the type 1 hard pan crust (Figure 4 (c)), where backscattering coefficient had a large increase between the flooded and the welldeveloped crust surfaces in the period from September 2017 to January 2018. On the other hand, for the soft pan crust in S1, Figure 4 (a), annual seasonality had little impact on $\sigma^{0}$.

Disregarding any scattering mechanism other than surface scattering for co-polarized configuration, the marked increase in VV-polarized $\sigma^{0}$ on site $\mathrm{S} 10$ can be explained as a strong increase in surface roughness parameter $s$ as shown by modelled $\sigma^{0}$ in Figure 3. In effect, the $8.8-\mathrm{dB} \sigma^{0}$ increase from -19.1 dB (17 Sep. 2017) to $-10.3 \mathrm{~dB}$ (15 Jan. 2018) on site S10 accounted for a roughness parameter $s$ increasing in the range 0.5 $\mathrm{mm}$ to $4.5 \mathrm{~mm}$ as followed from Figure 3. This increase led 


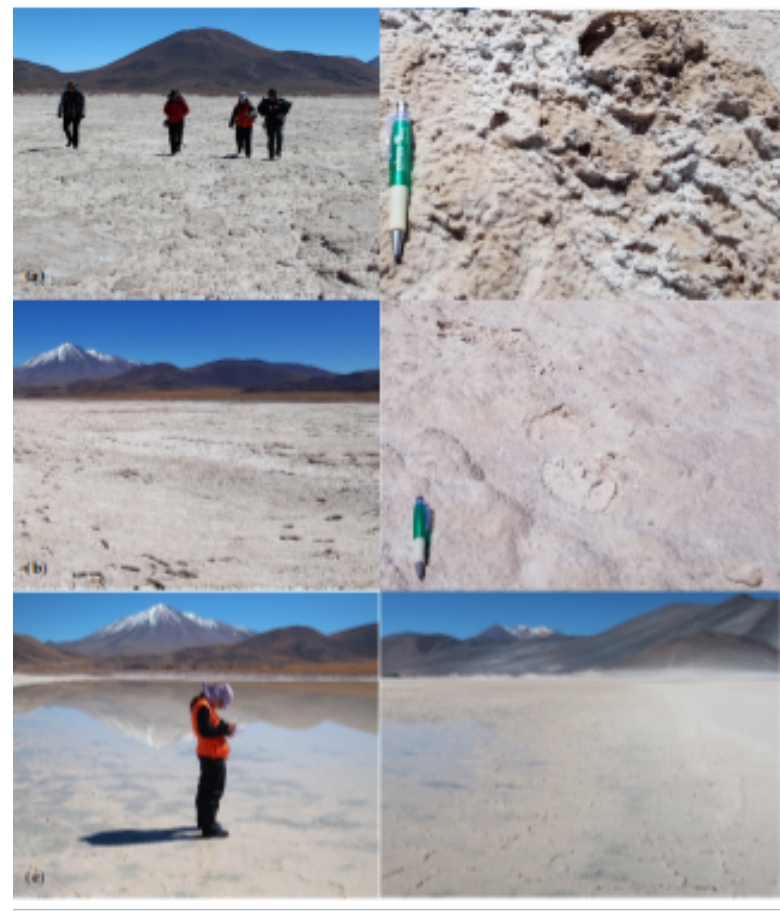

Figure 2. Types of salt crust observed in the field on April 3, 2018. (a) Upper panel: Hard pan crust 1, mixture of salts and sediments (rough surface); (b) Center panel: Hard pan crust 2 (gypsum and halite); (c) Bottom panel: Soft pan crust with contents of organic matter and thrust polygons by interaction with water.

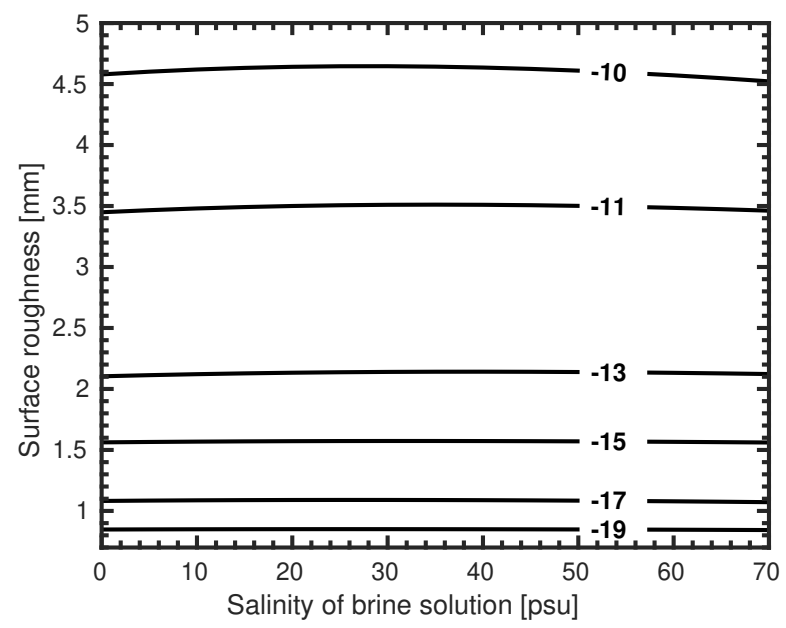

Figure 3. Contour plot in $\mathrm{dB}$ for C-band $(5.405 \mathrm{GHz})$ VV-polarized $\sigma^{0}$ modelled using the IEM2Mc with incidence angle $39.2^{\circ}$. Surface correlation length is ten times RMS height $(l=10 s)$.

to a rate of $2.20 \mathrm{~dB} /$ month over the 120 -day interval between the dates mentioned. Other roughness-related $\sigma^{0}$ variations are summarized in Table 1. For each site, the larger growth rate is found over the dry period after the snowfall at the beginning of the time series. When the water input is in the form of rainfall, as in February 2019, halite growth rate over the following dry period drops by about one half. Thus, the effect of water droplets dissolving previously grown salt aggregates had a major impact on $\sigma^{0}$. The combined effect of rainfall and snow- fall occurred between July and August 2018 led to intermediate rates of roughness variations.

Cross-polarized $\sigma^{0}$ wet-and-dry cycles appeared not so marked in comparison to co-polarized ones. Sentinel 1 instrument noise floor diminishes sensitivity for low $\sigma^{0}$. Instrument performance for the IW mode has a marked dependence with incidence angle (Torres et al., 2017). In effect, noise floor is about $-25 \mathrm{~dB}$ at $35^{\circ}$ which prevented sensitivity in the $\mathrm{VH}$ polarized returned power for the soft crust (Figure $4(\mathrm{a})$ ). Between $39^{\circ}$ and $40^{\circ}$ noise floor marginally improves to about $-27 \mathrm{~dB}$ which implied VH-polarized $\sigma^{0}$ to show some sensitivity to both hard crusts as shown in Figure 4(b) and (c). As snow accumulated over the surface, volume scattering markedly increased as seen at the beginning of the time series and over the snow events thereafter. Over the dry periods, VH-polarized $\sigma^{0}$ increased in the hard crusts possibly due to the rise of underground water that filled pore space within the crust.

\begin{tabular}{ccccc} 
Site & $\begin{array}{c}\text { Range } \\
\text { (start date / end date) }\end{array}$ & $\begin{array}{c}\text { Interval } \\
{[\text { day }]}\end{array}$ & $\begin{array}{c}\text { Increase } \\
{[\mathrm{dB}]}\end{array}$ & $\begin{array}{c}\text { Rate } \\
{[\mathrm{dB} / \mathrm{month}]}\end{array}$ \\
\hline \hline \multirow{2}{*}{1} & 23 Oct. 17 / 28 Dec. 17 & 66 & 4.56 & 2.07 \\
& 23 Feb. 18 / 27 Apr. 18 & 72 & 2.55 & 1.06 \\
\hline \multirow{2}{*}{6} & 29 Sep. 17 / 28 Dec. 17 & 90 & 3.71 & 1.24 \\
& 14 Feb. 18 / 02 Jun. 18 & 108 & 2.15 & 0.60 \\
& 18 Sep. 18 / 29 Dec. 18 & 102 & 2.77 & 0.81 \\
\multirow{2}{*}{10} & 17 Sep. 17 / 15 Jan. 18 & 120 & 8.80 & 2.20 \\
& 20 Feb. 18 / 08 Jun. 18 & 108 & 3.76 & 1.04 \\
& 18 Sep. 18 / 23 Dec. 18 & 96 & 5.01 & 1.57
\end{tabular}

Table 1. Monthly rate of increase of VV polarized backscattering coefficient $\sigma^{0}$ during dry periods where roughness variations at millimeter-scale are dominated by increasingly large halite aggregates.

\section{CONCLUSIONS}

Spaceborne synthetic aperture radar sensors are an important tool for monitoring vast environments in areas with difficult access such as highland salars. Although research has been done in salars at sea level, highland salars featured water input in the form of snow. The effect of snow and droplets on the dissolution of salt aggregates was demonstrated using radar acquisitions.

A 1.5-year-long time series with five acquisitions per month for the C-band constellation Sentinel $1 \mathrm{~A}$ and $1 \mathrm{~B}$ was used to monitor changes in the surface and subsurface of an highland salar. The high-density of data points enabled to compute halite growth rates by measuring the minimum and maximum $\sigma^{0}$ values and the day interval which that occurred at. Through modeling, changes in $\sigma^{0}$ were ascribed to changes in surface roughness given by salt crust development over the dry periods. With the sensitivity of backscattering coefficient to salt aggregates of few centimeters in size, the distinctive effect of rainfall and snow melt on the crust development was shown.

Further investigations using longer wavelength radar sensors would help understanding subsurface behaviour of salars. 

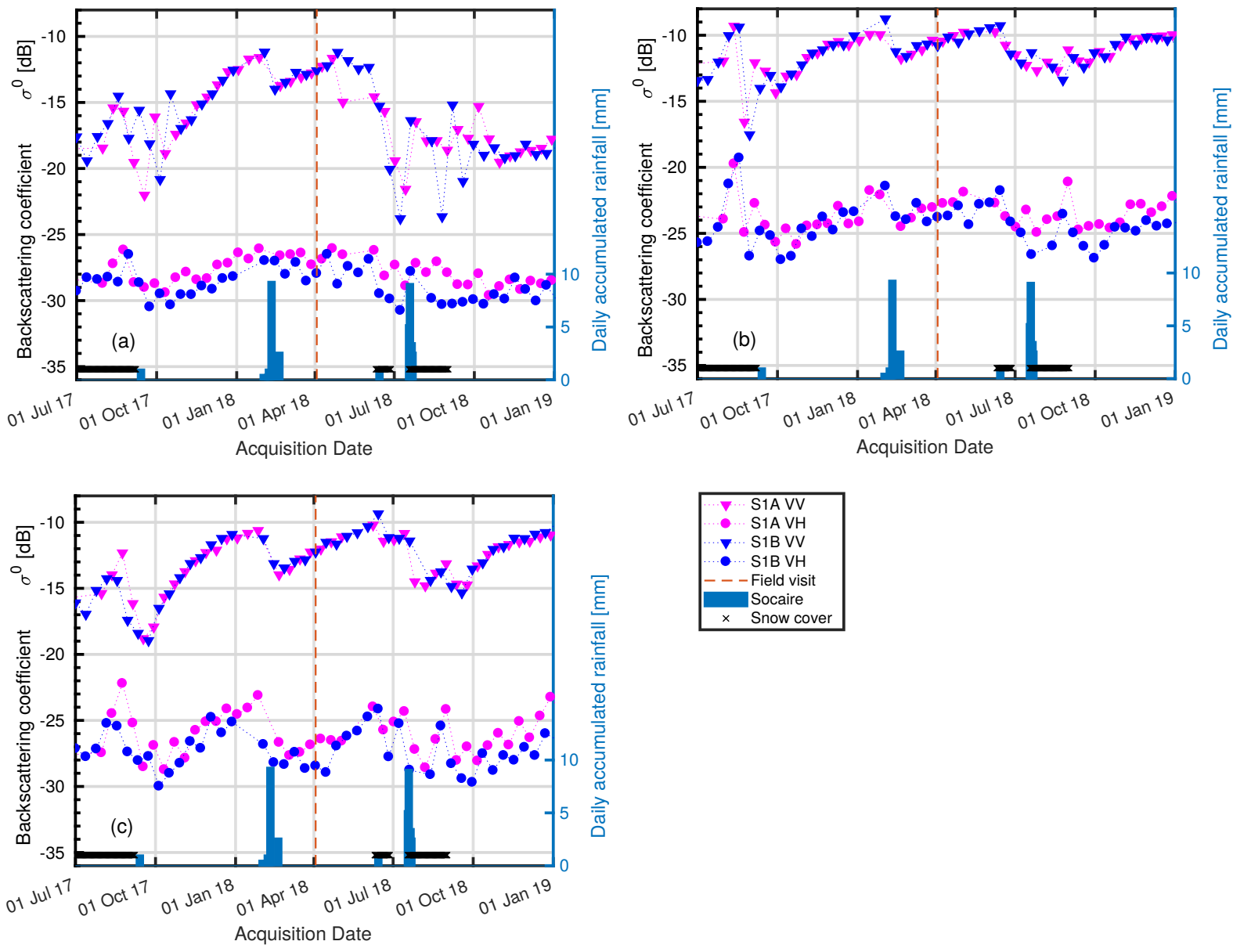

Figure 4. Sentinel 1 temporal backscattering observed over the salar. Sentinel 1A (magenta) and Sentinel 1B (blue) in ascending passes. VV polarization is indicated as triangles, and VH as circles. The vertical dashed line indicates field visit on April 3, 2018 (see

Figure 2). (a) Soft pan crust (site S1), the local incidence angle is between $35.2^{\circ}-35.4^{\circ}$; (b) Type 2 hard pan crust (S6), the local incidence angle is between $39.9^{\circ}-40.1^{\circ}$; (c) Type 1 hard pan crust (S10), local incidence angle is between $39.2^{\circ}-39.3^{\circ}$. Accumulated rainfall measured by Socaire station is shown as bars and snow occurrence is indicated as cross marks above the $\mathrm{x}$-ayis. 


\section{REFERENCES}

Agromet Home Page, 2019. Available online: http://agromet.inia.cl/estaciones.php (22 August 2019).

Álvarez-Pérez, J. L., 2012. The IEM2M rough-surface scattering model for complex-permittivity scattering media. Waves in Random and Complex Media, 22(2), 207-233.

Aly, Z., Bonn, F. J., Magagi, R., 2007. Analysis of the Backscattering Coefficient of Salt-Affected Soils Using Modeling and RADARSAT-1 SAR Data. IEEE Transactions on Geoscience and Remote Sensing, 45(2), 332-341.

Archer, D. J., Wadge, G., 2001. Modeling the backscatter response due to salt crust development. IEEE Transactions on Geoscience and Remote Sensing, 39(10), 2307-2310.

Barber, M. E., Grings, F. M., Álvarez Mozos, J., Piscitelli, M., Perna, P. A., Karszenbaum, H., 2016. Effects of Spatial Sampling Interval on Roughness Parameters and Microwave Backscatter over Agricultural Soil Surfaces. Remote Sensing, 8(6). https://www.mdpi.com/2072-4292/8/6/458.

Frison, P.-L., Paillou, P., Sayah, N., Pottier, E., Rudant, J.-P., 2013. Spatio-temporal monitoring of evaporitic processes using multiresolution C-band radar remote sensing data: Example of the Chott el Djerid, Tunisia. Canadian Journal of Remote Sensing, 39(2), 127-137. https://doi.org/10.5589/m13-018.

Fung, A. K., 1994. Microwave scattering and emission models and their applications. The Artech House remote sensing library, Artech House.

Herrera, C., Custodio, E., Chong, G., Lambán, L. J., Riquelme, R., Wilke, H., Jódar, J., Urrutia, J., Urqueta, H., Sarmiento, A., Gamboa, C., Lictevout, E., 2016. Groundwater flow in a closed basin with a saline shallow lake in a volcanic area: Laguna Tuyajto, northern Chilean Altiplano of the Andes. Science of The Total Environment, 541, 303 - 318.

Lasne, Y., Paillou, P., Freeman, A., Farr, T., McDonald, K. C., Ruffie, G., Malezieux, J., Chapman, B., Demontoux, F., 2008. Effect of Salinity on the Dielectric Properties of Geological Materials: Implication for Soil Moisture Detection by Means of Radar Remote Sensing. IEEE Transactions on Geoscience and Remote Sensing, 46(6), 1674-1688.
Liu, C.-A., Gong, H., Shao, Y., Yang, Z., Liu, L., Geng, Y., 2016. Recognition of salt crust types by means of PolSAR to reflect the fluctuation processes of an ancient lake in Lop Nur. Remote Sensing of Environment, 175, 148 - 157.

NASA Worldview Home Page, 2019. Available online: https://worldview.earthdata.nasa.gov (12 May 2019).

Risacher, F., Fritz, B., 2009. Origin of Salts and Brine Evolution of Bolivian and Chilean Salars. Aquatic Geochemistry, 15(1), 123-157. https://doi.org/10.1007/s10498-008-9056-x.

Ruch, J., Warren, J., Risacher, F., Walter, T., Lanari, R., 2012. Salt lake deformation detected from space. Earth and Planetary Science Letters, 331-332, 120 - 127.

Torres, R., Navas-Traver, I., Bibby, D., Lokas, S., Snoeij, P., Rommen, B., Osborne, S., Ceba-Vega, F., Potin, P., Geudtner, D., 2017. Sentinel-1 sar system and mission. 2017 IEEE Radar Conference (RadarConf), 1582-1585.

Troncoso, R., Ercilla, O., Carrasco, R., Vivallo, W., 2013. Estudio del potencial de litio en salares del norte de chile. Technical report, Servicio Nacional de Geología y Minería

Ulaby, F. T., Dellwig, L. F., Schmugge, T., 1975. Satellite microwave observations of the Utah Great Salt Lake Desert. Radio Science, 10(11), 947-963.

Ulaby, F. T., Long, D., Blackwell, W., Elachi, C., Fung, A., Ruf, C., Sarabandi, K., van Zyl, J., Zebker, H., 2014. Microwave Radar and Radiometric Remote Sensing.

Wadge, G., Archer, D. J., 2003. Evaporation of groundwater from arid playas measured by C-band SAR. IEEE Transactions on Geoscience and Remote Sensing, 41(7), 1641-1650.

Wadge, G., Archer, D., Millington, A., 1994. Monitoring playa sedimentation using sequential radar images. Terra Nova, 6(4), 391-396. https://onlinelibrary.wiley.com/doi/abs/10.1111/j.13653121.1994.tb00512.x.

Warren, J. K., 2016. Evaporites: A geological Compendium. Springer. 